\title{
Facilitative Approach to Teaching and Learning
}

\author{
Irina Avdeeva ${ }^{1}$, Olga Shutova $^{1}$, Larisa Adonina $^{1}$ and Tatiana Kokodey ${ }^{1, *}$ \\ ${ }^{1}$ Humanities Pedagogical Institute, Sevastopol State University, Sevastopol 299029, Russia \\ *Corresponding author.Email: tanya.kokodey@gmail.com
}

\begin{abstract}
Keywords: facilitation; learning; education; approach; teaching

\section{INTRODUCTION}

In the context of the personal development paradigm of the pedagogical process, the most important task of educational work is to facilitate the personal development of those who are taught. In this context, we consider development as a progressive transition from one level of personal capabilities to another. The most important ("the peak", if we use the terminology of A. Maslow) component of personal development is a positive personal change, which "in the proper sense of the word takes place during the transition to a new identity". As a result of acquiring a new identity, a person reveals a commitment to new values, beliefs, ways of acting, and even a different emotional type of response. Metaphorically, this phenomenon is called 'the transformation of a caterpillar into a butterfly'. And such events are extremely rare in the process of school education.
\end{abstract}

The facilitative approach to teaching and learning is introduced and analyzed in this study. Ideally, this approach should ensure progressive transition from one level of personal capabilities to another, the main component of which is a positive personal change during the transition to a new identity. As a result of acquiring a new identity, a person reveals a commitment to new values, beliefs, ways of acting, and even a different emotional type of response. As a result of the current study, we concluded that this suggested facilitative approach to working with human resources is flexible and comforting for an individual. This approach also increases efficiency of education as was illustrated by comparative analysis of two high schools using econometric methods. Following the facilitation principle of integration, we do not break or replace the existing human model of relationships with the world; we complement and expand the structure of his or her image of 'I'. Thus, there is a change of the hierarchy of structures of the inner experience.

\section{MATERIALS AND METHODS}

The changing face of teaching has moved away from didacticism to learning facilitation and with this is the need for teachers to play different roles and use new techniques $[1,2,3]$. Three main styles of teaching are propounded: didactic, Socratic and facilitative $[4,5,6,7,8,9,10,11]$. The diversity of styles provides a degree of flexibility that allows one to alter the task of teaching whether it is teacher-centered or student-centered. In this paper, we are using the qualitative methods of facilitative teaching. Facilitative teaching seeks to help [learners] "construct" meaning and come to an understanding of important ideas and processes. Teachers in this role guide [learner] inquiries into complex problems, texts, cases, projects, or situations. Their principal techniques are questioning, probing, and process-related commentary, with little or no direct instruction.

For instance, questioning is the essential component of many instructional methods including, of course, discussion and recitation. The influence of teachers' questions in the classroom is well documented by research and experience. In many respects, the primary effectiveness of the teacher lies in his or her ability to stimulate and guide students' thinking and involvement in classroom interaction related to topics, issues, and problems. The types of questions that elementary and secondary school teachers ask and the techniques and strategies they employ can make the difference between reflective, active learners and parroting, passive learners.

At the same time quantitative analysis in the research was based on two sets of econometric methods, those are regression analysis and time series analysis $[12,13,14,15]$. Regression analysis is a process for determining the relationship between a dependent variable and one or more independent variables. We use the linear regression model which allows the researcher to estimate the expected values of the dependent value when the independent values change. This is beneficial for forecasting or prediction. It can also help to find implied causal relationships. Time series analysis relies on examination of a graph which displays data points (as the name implies) over time. Its value in research is that it enables the extraction of meaningful statistics in order to create a predictive model. Trend is a pattern in the Time data that shows higher or lower values over a long period of time. By their nature, trends are temporary and nonrepetitive. Trend analysis helps to identify long term tendencies and project time series. 


\section{RESEARCH RESULTS AND ANALYSIS}

We researched the efficiency of two schools. We analyzed and compared the two in Sevastopol, Russia during the five-year period of time from 2017 till 2021. In one of the schools, \#4, the facilitative approach has been implemented since September 2017. To the contrary, in school \#2 the traditional teaching approach has been used. In order to compare the efficacy of both traditional and facilitative approaches, dependent variables $y_{2 t}$ and $y_{4 t}$ were introduced, which measured an average grade of a student of a graduating class for each school ( $t$ being time). One of the time series methods, namely trend analysis, was used in the open-source statistical software Gretl to obtain the models presented below. Trend of the variable $y_{2 t}$ is slightly sloping down as shown by the modeling results, figure 1

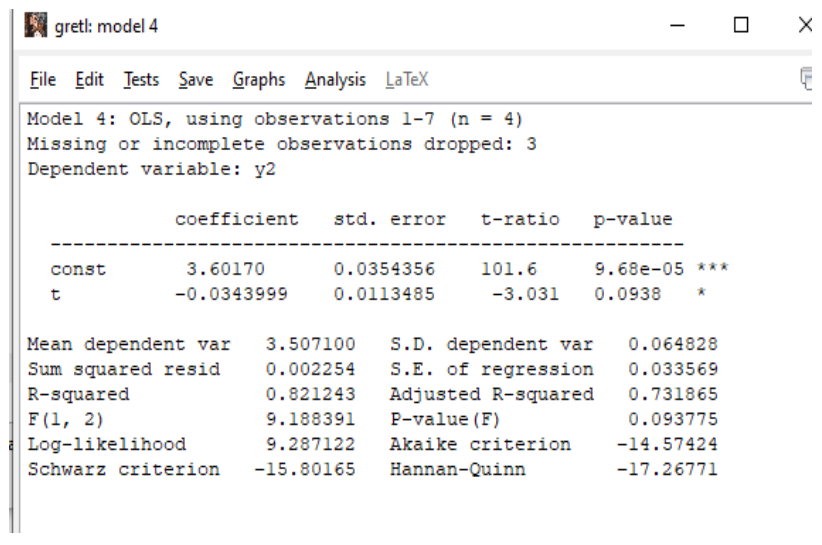

Figure 1. Modeling results for the variable y2t in Gretl

The obtained model (equation 1) $y_{2 t}=3,6-0,034 t$ is adequate according to the Fischer F-criteria, while the parameters according to the Student T-criteria is at the $10 \%$ significance level. Thus, this model can be used for projections, those are 3.39 in the year 2022 and 3.36 in the year 2023.The efficiency indicator is slowly decreasing in time for the school \#2 where facilitative approach wasn't introduced.

$\mathrm{y}_{2 \mathrm{t}}=3,6-0,034 \mathrm{t}$

t- time (year number);

$y_{2 t}$ - averaged grade of a student of a graduating class for school \#2.

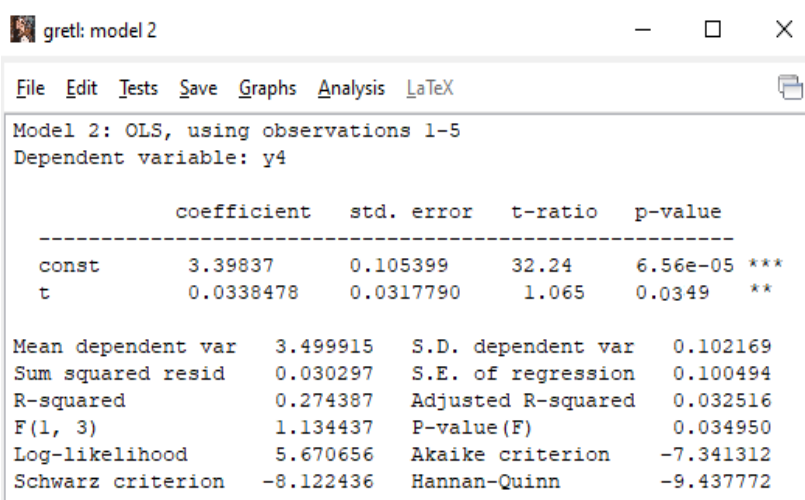

Figure 2. Modeling results for the variable y4t in Gretl

The obtained model (equation 2) is adequate according to the Fischer F-criteria, while the parameters according to the Student T-criteria are at the 5\% significance level. Thus, this model can be used for projections, those are 3.6 in the year 2022 and 3.635 in the year 2023. The efficiency indicator is slowly growing in time for school \#4 where the facilitative approach was used in the teaching process.

$$
\mathrm{y}_{4 \mathrm{t}}=3,39+0,034 \mathrm{t}
$$

t- time (year number);

$\mathrm{y}_{4 \mathrm{t}}$ - averaged grade of a student of a graduating class for school \#4.

It can also be inferred from the results above that in the long-run the facilitative approach can increase the teaching efficiency of a school, all other conditions and factors being the same. Here, we illustrate this in graph form in figure 3 .

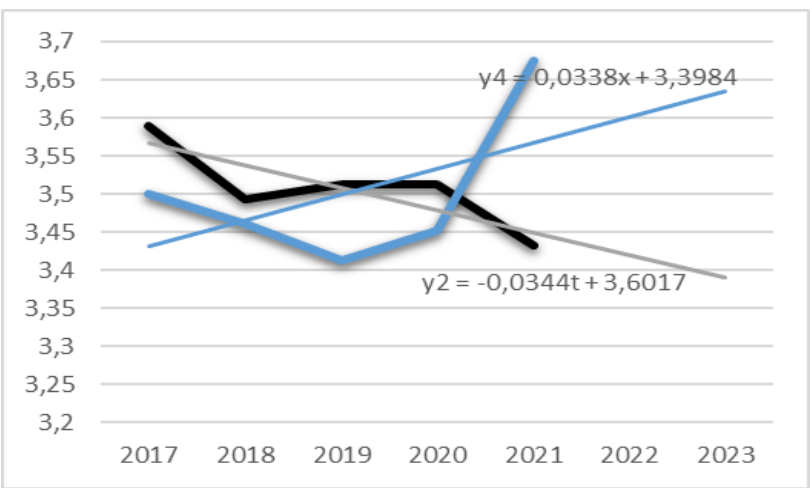

Figure 3. Dynamics and projections of $y_{2 t}$ and $y_{4 t}$

It can also be noted that there were some problems implementing the facilitative approach in school \#4. One of the most serious obstacles encountered was facilitating positive personal changes in the system of non-constructive / non-adaptive intrapersonal attitudes, student selfperceptions and student self-assessment of their capabilities in the educational environment. As a rule, these ideas are 
very stable, since they were formed over a long time and are the individual result of adaptation to specific circumstances of life (having the significance of the parameters of the social situation of development), which in everyday life in their basic characteristics are practically little changed.

To such - 'stabilizing' - parameters of the social situation of development include: the same composition of actual carriers of the requirements of the social situation of development (class staff, parents, teachers, representatives of the reference group), the usual style of communication and communicative and evaluative expectations for all participants of the educational (socialization) process, wellestablished configurations of role positions in typical situations of interaction... These features of life determine a fairly stable (and therefore, limited) a fan of alternatives to behavioral and emotional responses of participants in the educational process. In the range of this fan a person builds their typical behavior (implements your psychological style). However, it is noted that first of all, situations that are radically new, 'transitional', unpredictable provoke the launch of personal change processes.

\section{DISCUSSION}

\subsection{The problems with tradition}

According to the circumstances mentioned above, under the conditions of school education, correctional and readaptation work related to the change of personal attitudes, the opening and development of new lines of personal development is possible, but at the same time they are not very effective. First of all, the crisis of the modern childcentered model of school psychological service is associated with these circumstances. A child, especially a teenager, needs, first of all, to change the stimulating parameters (requirements) of the social situation of development in order to discover and accept new development resources, to create motivation for selfchange based on the subjective use of these resources, and to acquire a new identity. Changes in the social situation of development can be expressed both in the change in the hierarchy of actual requirements, and in the change in their content (the new content is presented to the child as a set of new / different expectations from significant others). At the same time, the facilitation of personal development, in addition to presenting new requirements-expectations, also consists in providing a range of alternative opportunities for choosing acceptable (from the point of view of the recipient of educational influences) responses to the new requirements of the social situation of development. "Providing opportunities" involve both organizing life situations in which it is possible to implement new ways of behavioral and emotional response, and special work to identify and present to the child those features that previously were not considered as personal resources and were not used to create ways of self-realization in everyday life situations. The problem is that teachers and educators are not in a hurry to change their expectations in relation to the pupil, starting the mechanism of positive personal changes. Firstly, because of the above reasons ("As you show yourself to teachers at the beginning of the year, so they will continue to treat you"), and secondly, not everyone is familiar with new technologies for our school to facilitate personal changes. The educational process of the children's camp provides quite a lot of opportunities to solve this problem.

\subsection{The opportunity of Innovation}

In contrast to school, in children's camps, for example, such as the Federal State Budget Educational Institution the International Child Center "Artek", in situations of completely new group contacts, there is a real possibility of maximum immersion of the child in a new social situation of development. It seems that the idea is not new: new acquaintances, new contacts create an opportunity to implement new behaviors - 'the slate clean'. They must communicate new expectations to the child... However, in new situations when people are not familiar with each other, in situations of uncertainty, a person, as a rule, without realizing it, implements those methods of behavioral and emotional response that are familiar to him, are 'their own', tested in their own life. Representatives of the social environment react accordingly to these psychological styles, and their bearer (again without realizing it) selects and confirms from the reactions of the environment those that are familiar to him, which are similar to those with whom he has already met in the 'previous life'. This is because in situations of communicative uncertainty and related tension, a person (especially an insecure one - and teenagers, for the most part, show increased anxiety about new communications) 'grasping at straws', i.e., the person who is not sure of what to do try to use familiar (even if not the most successful) proved actions which he has done before. And there is a communicative situation that is not fundamentally different from the one in which the child was self-actualized earlier. I.e., the 'discovery' of new resources for personal growth does not occur. It should be noted that sometimes children try to act in a new role: shy children behave themselves as cheeky ones, a poor pupil acts as 'a son of a very rich person, like an oligarch', etc. But such a 'new' way of life cannot be regarded as an experience of mastering a new personal resource, because the subject himself perceives it as a temporary mask. Moreover, the need to wear a mask, to control the process of its 'wearing' (ensuring that new comrades 'do not recognize' the true features of the 'wearer') leads to increased intrapersonal tension ('a spy in the enemy's camp') and, at least, to a subconscious negative emotional marking of the experience of a completely worthy new social role. And negative emotional marking (especially subconscious) is an essential obstacle to the activation of personal development resources. 
In this regard, it is very promising to work on the safe testing of ways of self-realization in completely new types of activities for a particular person. That is, in such cases, which were not even considered as successful (or even available) by the subject. The key words in this thesis are 'safe testing'. At the same time, the quality of the resultproduct of this new activity does not matter. The main thing is a positive experience of implementation in a new, unexpected sphere. The facilitator (educator, mentor, counselor) should ensure positive marking of the new social role, using techniques of "situational linking" of the encouraged behavioral responses of a teenager to a specific situation of camp life. It is important not to go beyond the specific situation, not to translate the assessment of behavior to the level of basic personal qualities. It is at these moments that it becomes really possible to independently identify the child with those features that they previously did not recognize as personal resources.

\subsection{Developing facilitation skills}

Facilitation skills are the abilities used to provide opportunities and resources to a group of people that enable them to make progress and succeed. Under summer camp conditions, counselors need to develop facilitation skills. A few of these skills are discussed below.

The first skill is the ability to set guidelines. This binds the group to a shared common goal. Progress is faster when everyone has a common appreciation of the goal and knows what the facilitator desires as an outcome.

The second skill is neutrality. The facilitator should remain unbiased and non-judgmental in order that the team participates in decision making. The facilitator guides rather than directs. The success of the team is paramount, no matter if the decisions might be flawed.

The third skill is an encouraging nature. Every group has shy participants. The objective is to have everyone contribute. It is often said that "two heads are better than one". In this case, all heads are better than just a few.

The fourth skill is preparedness. A facilitator who anticipates the group's needs can provide needed resources in order to maintain focus on the goal.

The fifth skill is flexibility. Nothing is as constant as change and a good facilitator needs to know when to adapt to the changes in mindset that might occur.

Finally, facilitators need to develop good listening skills. This involves listening to all opinions and listening fully to everyone. People respond positively when their voices are appreciated. The opposite is also true.

\section{CONCLUSION}

As a result, it should be emphasized that this approach to working with resources is soft and comfortable for the individual. In accordance with the facilitation principle of integration, we do not break or replace the existing human model of relationships with the world, we complement and expand the structure of his image of 'I'. Thus, there is a change of hierarchy of structures of inner experience. Of course, it is necessary to provide special psychological, organizational and pedagogical support for these processes so that personal changes are positive. Technological methods and algorithms of such support are presented in the corresponding (facilitating) pedagogical technologies.

\section{REFERENCES}

[1]M. Banning, "Becoming a Critically Reflective Teacher," John Wiley \& Sons, Incorporated, 2017.

[2]P. Baepler, D. Brooks, J. Walker, “Active Learning Spaces," New Directions for Teaching and Learning, no. 137. San Francisco: Jossey - Bass, 2014.

[3]S. D. Brookfield, S. Preskill, "The Discussion Book: 50 Great Ways to Get People Talking". San Francisco: Jossey - Bass, 2016

[4]M. Banning, M. "An illuminative evaluation of the teaching and learning experience of participants' teaching and studying on an independent nurse prescribing course," unpublished.

[5]A. Darder, P. Mayo, and J. Paraskeva, "International Critical Pedagogy Reader”. New York: Routledge, 2015.

[6]A. Fejas, "The Confessing Academic and Living the Present Otherwise: Appraisal Interviews and Logbooks in Academia." European Educational Research Journal 15 , no. 2,2016 , pp. $1-15$.

[7]Reeves, Scott (01/12/2016). "Using a metaethnographic approach to explore the nature of facilitation and teaching approaches employed in interprofessional education". Medical teacher (0142159X), 38 (12), p. 1221

[8]Gormally, Cara (01/05/2016). "Uncovering Barriers to Teaching Assistants (TAs) Implementing Inquiry Teaching: Inconsistent Facilitation Techniques, Student Resistance, and Reluctance to Share Control over Learning with Students". Journal of microbiology \& biology education (1935-7877), 17 (2), p. 215.

[9]Hatlevik, Ida K.R., and Ove E. Hatlevik. "Examining the Relationship Between Teachers' ICT Self-Efficacy for Educational Purposes, Collegial Collaboration, Lack of Facilitation and the Use of ICT in Teaching Practice." Frontiers in Psychology, 13 June 2018.

[10]Caprara, G. V., Barbaranelli, C., Steca, P., and Malone, P. S. (2006). Teachers' self-efficacy beliefs as 
determinants of job satisfaction and students' academic achievement: a study at the school level. J. Sch.

Psychol. 44, 473-490.

[11]Wastiau, P., Blamire, R., Kearney, C., Quittre, V., Van de Gaer, E., and Monseur, C. (2013). The use of ICT in education: a survey of schools in Europe. Eur. J. Educ.48, 11-27.

[12]Varian, H. R. (2014). Big Data: New Tricks for Econometrics. The Journal of Economic Perspectives, 28(2), 3-27.

[13]Mullainathan, Sendhil, and Jann Spiess. "Machine Learning: An Applied Econometric Approach.” The
Journal of Economic Perspectives 31, no. 2 (2017): 87106.

[14]Kleinberg, Jon, Jens Ludwig, Sendhil Mullainathan, and Ziad Obermeyer. 2015. "Prediction Policy Problems." American Economic Review 105(5): 49195.

[15]Grangeat, M., and Gray, P. (2008). Teaching as a collective work: analysis, current research and implications for teacher education. J. Educ. Teach. 34, 177-189. 